\title{
Strategies for Listening and Speaking Teaching of College English under Professional Interpretation Pattern
}

\author{
Xiaojin Cui \\ Haikou College of Economics, Haikou, 571127, China
}

Keywords: professional interpretation pattern, college English, listening and speaking teaching

\begin{abstract}
The grammar-translation method trained used in the traditional English listening and speaking classes cannot meet the needs of college English to cultivate practical talents. The reform to English listening and speaking teaching pattern is imperative. The professional interpretation method is just applied into English listening and speaking teaching under such historical background. This method plays an important role in promoting better participation of students into practice in class and comprehensively improving students' application ability in English listening and speaking. Based on a specific analysis on positive effects of the professional interpretation pattern on English listening and speaking classroom teaching, the author discussed in details relevant strategies for English listening and speaking teaching, and expected to promote the teaching of college English to cultivate more practical talents for the society.

Listening and speaking courses of college English can not only cultivate reading and writing competence of students but also gradually help students to realize the parallel state between English listening \& speaking competence and reading \& writing competence of students. Besides, these courses also play an important role in social practice of students' English competence. In this paper, the author expected to provide certain ways of implementation for the listening and speaking teaching of college English under the professional interpretation pattern through a brief analysis on the practical role of professional interpretation in the listening and speaking classroom teaching of college English, so as to make the listening and speaking teaching to play a more excellent role in cultivating students' comprehensive application competence of English language.
\end{abstract}

\section{Positive Effect of the Professional Interpretation Pattern on the Teaching of English Listening and Speaking}

(I) Play a role in aided teaching of oral expression of English

In the implementation process of English listening and speaking classroom teaching, the following scenes often appear: when several students are communicating with each other in English, other persons in the communication still fail to have a correct understanding of the speaker's meaning even through it is repeated or even transformed into another statements. Under this circumstance, the speaker always uses interpretation to express the original meaning considering the needs to save the learning time so that other members can understand. Similarly, a student will automatically ask other teachers or students around for help, when he cannot understand other's oral expression. The teachers or students are asked to provide relevant reference to his understanding of teaching upon reasonable interpretation, making the communication in the process of teaching to proceed in a normal state. To some extent, this conscious English interpretation behavior of teachers and students is served as the lubricant of the listening teaching of spoken language, which not only provides certain convenience for students to have a deep understanding of text meanings but also improves students' practical competence of English listening and speaking to some extent. Imperceptibly, this consciousness also promotes the effective realization of English listening and speaking teaching.

(II) Reasonably supplement communicative approaches

The pattern of group-teaching is generally adopted for college English teaching in most Chinese colleges and universities. There are certain limits to the realization of teaching effectiveness. In the process of teaching, it is usually difficult for teachers to solve students' problems in the life and the learning one by one according to actual learning conditions of different students. Under the 
promotion of social needs, however, the listening and speaking classroom teaching of college English has already began to lay emphasis on the creation of opportunities to participate into communicative activities and practices for students in the classroom teaching. In this communicative activity, it certainly will give rise to sentence understanding, lexical representation and other problems, no matter in the dialogue of two students or the analysis and discussion on a certain question in a group, the setting of a debate / lecture or any other specific ways of implementation. However, the professional interpretation method will become the most direct and the most convenient means of mutual interpretation at this moment, which plays a reasonable supplementation role in teachers' teaching transmission and exchange \& practice with students.

In short, the professional interpretation teaching works as a medium in the listening and speaking teaching of college English. Besides the promotion of specific practices of the classroom teaching, the professional interpretation teaching can also enrich listening and speaking classroom activities of college English. This method is of important practical significance for the effective development of classroom teaching.

\section{Strategies for the Implementation of English Listening and Speaking Teaching under the Professional Interpretation Pattern}

(I) English listening and speaking teaching should tamp the foundation of pronunciation under the professional interpretation pattern.

The English listening and speaking classroom interpretation teaching has non-photorealistic features. Certain differences exist between the applying environment, situation and context of interpretation in the classroom teaching and the practical interpretation. Therefore, it is necessary to set multiple bedding teaching contents to create scientific and rational high-quality conditions for the implementation of interpretation teaching, letting students gradually develop the habit of interpretation in the process of listening and speaking teaching, so as to cultivate the interpretation accomplishment and improve the comprehensive application competence of English language at the same time. In the following paragraphs, an analysis is made onto specific teaching strategies for the pronunciation contents to be stressed in the teaching of English listening and speaking.

1. Attach importance to the basic pronunciation teaching

(1) Guide the students to seize the intonation: Chinese students must attach importance to the intonation teaching, and lay a solid foundation for intonation in the classroom teaching while stressing the interpretation teaching in the teaching process of English listening and speaking. At first, teachers should guide students' pronunciation practices in the teaching practice of college English listening and speaking, letting students master pronunciation positions and correct pronunciation shape of mouth of all basic phonemes in the initial stage of learning by imitation and practice accurate pronunciation as much as possible. In the classroom teaching, teachers can apply the way of multimedia graphical representation or teacher demonstration of practical case, so as to allow the students to have a detailed understanding of their vocal organs, and consciously apply their vocal organs in pronunciation practice during the imitation or practice. This method can not only enhance the mastering capacity of intonation during the pronunciation but also play a role in aiding the teaching and training of vowels and consonants in the next stage. It's worth noting that teachers should master the learning schedule of students, organize the students to imitate the teachers' pronunciation upon a detailed understanding of places of articulation and shapes of mouth, and avoid a rush for quick results or any influence on the actual teaching effect. Secondly, for the students having unfavorable pronunciation habits in the early teaching, teachers should allow the students to recognize the greater difficulty in changing these habits than developing new ones, guide the students to relearn about wrong pronunciation, and positively observe, experience and practice correct pronunciation step by step, especially in the comparative teaching of vowel and consonant pronunciation. Teachers should give careful and systematic explanation of characteristics about the two kinds of pronunciation, and timely allow the students to form correct recognition of intonation through classroom practices and to improve their competence of English listening and 
speaking at college.

(2) Give a brief explanation of pronunciation rules, and lay a foundation for the deepened interpretation teaching in the later stage: in the teaching process of English listening and speaking, teachers should pay attention to three kinds of interpretation pronunciation rules: continuation, loss of plosive and phonic assimilation. In the instruction process of pronunciation rules to non-English majors, English teachers can deepen their understanding through some practical cases or some simple word groups and phrases, so as to create conditions for the future studies.

2. Perform comprehensive training for pronunciation of English

(1) Train sense groups: in the oral training of traditional language listening and speaking courses, the students will always read off a sentence without a pause when required by the teachers to read aloud the sentence. This kind of reading is completely free from any sense of rhythm, which is unfavorable for the students' understanding and mastering of the sentence contents. Under such circumstance, teachers should guide the students to divide the sentences to be read into several parts according to the semantics and relevant grammatical relations. Each part is a sense group of one sentence. In the process of reading aloud, the students can make reasonable pauses between sense groups, making the sentence expression to be consistent with thinking activities of the students, so as to gradually strengthen the "sense-group consciousness" in the thought consciousness of students, experience the existence and practicability of spoken English, and improve the oral expression level of students.

(2) Train the intonation of sentences: in the teaching of this knowledge point, teachers should explain for the students similarities and differences of falling tone, rising tone and flat tone in English Intonation, make an in-depth analysis on the matching and combination relations between more complicated intonations, and make interpretation in English listening and speaking teaching more civilian and in conformity with the demands of social development for English talents. At the same time, teachers should also explain to the students that different intonations may present different meanings and emotional colors, display these differences through the pronunciation of different intonations by the teachers, enhance the emotional features of intonation teaching, and make the classroom to be more expressive.

(II) English listening and speaking teaching should pay attention to teaching in different stages under the professional interpretation pattern.

1. Pay attention to classroom teaching

Classroom is served as the main base for the students to improve knowledge reserves and learning capacity. Therefore, teachers must lay emphasis on classroom teaching in the process of teaching, maximize the improvement to the classroom teaching effects, and guarantee the students' initiative in classroom learning. First of all, teachers should make it clear for the purpose of the interpretation teaching method in English listening and speaking teaching, guide the students to form a correct understanding of principles, ways and relevant skills of interpretation, create opportunities for the students to participate into teaching activities as much as possible, take the students as the center of all teaching activities, make the students to find out and solve relevant problems in the teaching through the combination of multiple teaching patterns, and enhance the comprehensive learning capacity of students.

(1) Combine reading aloud, conversation and interpretation practices

Reading aloud and conversation belong to teaching patterns frequently seen in English listening and speaking teaching at college. In classroom teaching, teachers combine this teaching pattern with the comprehensive English teaching, and require the students to be involved in reading aloud and situational dialogue according to the teaching contents. In terms of the reading aloud teaching in the classroom teaching practice, teachers can allow other students to carefully record incorrect pronunciations of the reader according to the reader's contents and to correct according to learnt knowledge. Moreover, teachers can give secondary guidance to the students in terms of the corrected contents, till the students can correctly read and pronounce the texts, so as to enhance the self-examination and other-examination competence. For the dialogue teaching, teachers should take the interpretation of sentence as the implementation medium of dialogue teaching, enhance the 
students' understanding and mastering of knowledge points with the mode of interpretation sentence-making, make the students to enhance their English listening and speaking competence in interpretation practices through the guidance to the students for conscious translation between English and Chinese in the classroom, and improve the comprehensive application competence of the students with respect to English language.

(2) Enhance the mastering of basic text knowledge about English listening and speaking teaching

Textbook is served as the main source for the students to expand their knowledge reserves. Basic knowledge in the texts plays an important role in aiding the studies of students. For English language teaching, the interpretation teaching contents are sourced from intensive reading texts in English textbooks of the students. The development of interpretation training by the students from intensive reading texts can alleviate the students' academic stress, and make the teaching to achieve favorable effects through simple guidance. According to the survey on the English listening and speaking teaching of college students under the interpretation teaching pattern, interpretation mistakes of the students in English listening and speaking training are usually caused by weak mastering of basic knowledge about the texts. For the improvement to the teaching level of English listening and speaking under the professional interpretation pattern, therefore, the teachers should enhance the solidification of matching relationships between vocabularies and words in English texts, deepen structural relationships among word groups, phrases and Chinese-English language families in the interpretation, correctly understand structural relationships between sentences of texts through the analysis on relevant statement syntax structures, and strengthen the classroom teaching effects.

(3) Design relevant electronic texts for classroom teaching, and improve the teaching effectiveness through sight translation

Sight translation is also called translation upon the sight of materials. To be specific, teachers should allow the students to interpret the contents of manuscripts while watching multimedia manuscripts displayed by teachers, which is of favorable effects on the improvement to interpretation synchronism of the students. In this teaching activity, video translation training, as a transitory stage of intensive reading teaching and interpretation teaching, can not only provide relevant material preparations for conscious interpreting training of the students but also enhance the students' sensitiveness toward the transformation of sentence pattern between Chinese and English, providing relevant guarantee to the effectiveness of classroom teaching. The feature of this teaching pattern is that it can effectively utilize the instant-presenting function of electronic text to combine fast interpretation training in listening and speaking teaching with relevant trainings for error correction, design a scientific and reasonable self-learning framework for classroom learning, make the finishing point for the practice of listening and speaking teaching from the perspective of translation reference, mobilize the students' initiative for studies of English listening and speaking, create a favorable teaching environment for teaching, and realize the cultivation and improvement of interpretation teaching for the students' English listening and speaking ability to the maximum extent.

2. Attach importance to the development of after-class teaching activities

After-class activities of English listening and speaking teaching under the professional interpretation pattern can be mainly developed through such patterns as speech contest, English debate, drama demonstration and exchange of English corner, so as to unconsciously cultivate English listening and speaking ability of the students in the after-class life. Under normal circumstances, the three teaching patters (i.e. speech contest, English debate and drama demonstration) will not be adopted by the teachers in classroom teaching at college. Instead, the teachers can only give relevant guidance to the teaching results through the teaching of after-class activities, and play a role in guiding the students in terms of the establishment of psychological quality, reaction capacity, logical thinking capacity, self-confidence and team spirit while improving the students' level of oral English learning. In the specific implementation process, the teachers can also regularly arrange these activities under the assistance of the school and relevant departments, so as to erect a demonstration stage for the students and create conditions for the 
application of the students' comprehensive language competence. For the interaction activity of exchange in the English corner, it is a product with obvious personality characteristics in college English listening and speaking teaching. Under the help of English teachers, the students can set English corners promoting the realization of teaching results at any time according to the needs of teaching activities, so as to let the students improve their English listening and speaking level in mutual help, and create a high-quality communication platform for the students to master better learning methods.

\section{Conclusion}

To sum up, for favorable effects, the listening and speaking teaching of college English under the professional interpretation pattern should make an associative exploration for the classroom teaching pattern and the after-class teaching pattern, improve the students' learning ability in the classroom, improve their inspiration ability of English listening and speaking studies after class, comprehensively utilize the learning time at college, and improve the effectiveness of English listening and speaking teaching.

\section{References:}

[1] Rao Qiaoying, Application of Interpreting Training in Listening and Speaking Teaching of College English [J], Journal of Mudanjiang College of Education, 2014 (12);

[2] Ren Li, Reflection on Ecology of Interpreting Teaching of College English under the Environment of Multimedia [J], Computer-Assisted Foreign Language Education in China, 2012 (2);

[3] Gong Qiangwei and Li Hao, Application of Interpretation Method in Listening and Speaking Courses of College English [J], Journal of Lanzhou Institute of Education, 2012, 28 (5);

[4] Li Xueqin and Miao Tianshun, Application of Short-term Memory and Note-taking Training in Listening and Speaking Teaching of College English [J], Academy, 2014 (8);

[5] Lv Zhuotong, Summary of Multi-modal Teaching Researches on College English at Home and Abroad in the Previous Five Years [J], Overseas English, 2014 (12) 